\title{
HUNIAN VERTIKAL PRODUKTIF DI PAPANGGO, JAKARTA UTARA
}

\author{
Elda Widiastri ${ }^{1)}$, Stephanus Huwae ${ }^{2)}$ \\ 1)Program Studi S1 Arsitektur, Fakultas Teknik, Universitas Tarumanagara, eldawidiastri@gmaill.com \\ 2) Program Studi S1 Arsitektur, Fakultas Teknik, Universitas Tarumanagara, stephanush@ft.untar.ac.id
}

Masuk: 03-07-2021, revisi: 15-08-2021, diterima untuk diterbitkan: 23-10-2021

\begin{abstract}
Abstrak
Manusia merupakan makhluk sosial yang hidup berkelompok dan saling membutuhkan satu sama lain. Manusia membentuk sebuah keluarga dan hidup bersama di dalam satu ruang lingkup hunian. Angka populasi manusia di dunia semakin meningkat tiap tahunnya terutama di pusat kota besar. Jumlah penduduk yang meningkat menyebabkan ketidakseimbangan antara kebutuhan warga kota dengan pasokan energi dan lahan yang tersedia di perkotaan besar di Indonesia seperti Jakarta. Pasokan pangan warga kota mengandalkan sumber dari luar atau pinggiran kota, yang distribusinya menghasilkan peningkatan emisi gas rumah kaca. Papanggo, Jakarta Utara sendiri merupakan daerah padat penduduk yang memiliki tingkat ekonomi menengah ke rendah dengan tingkat produktivitas warganya yang kurang. Berdasarkan Pusat Statistik Indonesia pada tahun 2020, daerah Papanggo yang berada di Tanjung Priok, Jakarta Utara mencatat jumlah penduduk sebesar 46.141 jiwa dengan luas total $2,80 \mathrm{~km}^{2}$. Ditinjau dari data tersebut, Papanggo merupakan daerah yang cukup padat di DKI Jakarta dengan kepadatan penduduk $16.478,9 \mathrm{jiwa} / \mathrm{km}^{2}$ dan hanya sebagian kecil warganya bekerja sebagai petani kota. Dari beberapa masalah yang ada di Papanggo, dilakukan pendekatan dimulai dari tahap observasi, lalu dilanjutkan dengan analisis tapak. Program diolah dengan metode kontekstual tempat, cross programing, sedangkan penerapan metode desain biophilic. Prinsip Biophilic yang menghargai alam dapat memberikan kenyamanan dan rasa aman, diharapkan dapat meningkatkan produktivitas dan kesehatan fisik maupun psikis pengguna. Kesimpulan pada proyek bangunan ini adalah dengan berusaha memberikan ruang hunian vertikal baru pada Kawasan Papanggo agar warga kota bisa tinggal dan tetap produktif menghasilkan energi dan bahan pangan secara mandiri dengan memanfaatkan sumber daya alam dan manusia setempat.
\end{abstract}

Kata kunci: Biophilic; Hunian; Papanggo

\begin{abstract}
Humans are social creatures who live and need each other. Humans form a family and live together in a space. The number of human population in the world is increasing every year, especially in big cities. The increasing population causes an imbalance between the needs and the available energy, land supply in large urban areas in Indonesia such as Jakarta. City food supply relies on external sources, the distribution causing increased greenhouse gas emissions. Papanggo itself is a densely populated area that has a medium to low economic level with a low level of productivity of its citizens. Based on the Indonesian Statistics Center in 2020, the Papanggo area in North Jakarta recorded a population of 46,141 people with a total area of $2.80 \mathrm{~km}^{2}$. Judging from these data, Papanggo is a dense area in Jakarta with a population density of $16,478.9$ people $/ \mathrm{km}^{2}$ and only a small proportion of its residents work as urban farmers. From several problems that exist in Papanggo, an approach is carried out starting from the observation stage, then continued with site analysis. The program is processed using a place contextual method, cross-programming, and biophilic design methods. Biophilic principles that respect nature can provide comfort and a sense of security, is expected to increase users' productivity and health. The conclusion of this project is to try to provide new vertical residential space in Papanggo so that city residents can live and remain productive in producing energy and food independently by utilizing local natural and human resources.
\end{abstract}

Keywords: Biophilic; Papanggo; Residence 


\section{PENDAHULUAN}

\section{Latar Belakang}

Manusia membutuhkan suatu tempat tinggal yang tetap menjaga produktivitasnya di saat mobilitas manusia terganggu. Perkotaan besar seperti DKI Jakarta mengalami tingkat urbanisasi yang tinggi dan menyebabkan tingginya tingkat kepadatan penduduk di DKI Jakarta. Hal tersebut mengakibatkan ruang perkotaan semakin padat. Perbandingan yang tidak seimbang antara ketersediaan ruang perkotaan dengan jumlah penghuninya, berdampak pada menurunnya kualitas lingkungan di perkotaan dan kesejahteraan masyarakat (Pramudito, Lanang, \& Jeffry, 2018). Kota Jakarta mengandalkan hunian vertikal untuk mengatasi masalah keterbatasan lahan yang ada akibat tingginya kepadatan penduduk. Namun hunian vertikal hanya berfungsi sebagai tempat tinggal saja, tanpa ada fungsi lainnya yang mendukung lingkungan dan kesejahteraan warga kota lebih lanjut.

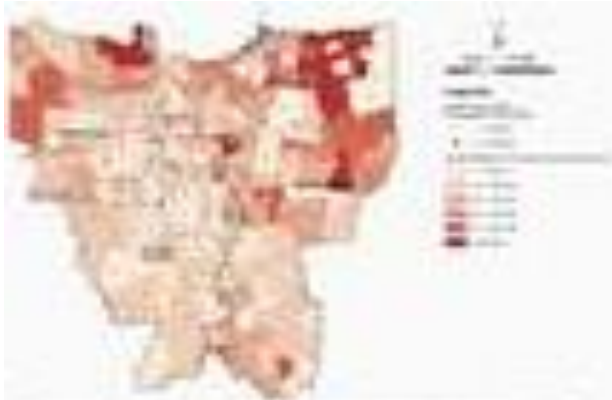

Gambar 1. Peta penyebaran kasus COVID-19 di DKI Jakarta Sumber: Kompas

Pandemi COVID-19 menjadi wabah global yang sedang dihadapi oleh seluruh dunia. Seluruh bidang kehidupan terpengaruh, mulai dari kesehatan manusia dan interaksi sosial manusia. Papanggo, Jakarta Utara merupakan salah satu daerah yang terkena dampak lebih parah jika dilihat dari peta penyebaran COVID-19. Akibat pandemi ini, manusia dipaksa untuk berdaptasi agar tetap bertahan hidup. Pertanian kota akan menjadi satu alternatif untuk bertahan hidup dalam kehidupan manusia (Fauzi, Ichniarsyah, \& Agustin, 2016). Pertanian kota dapat membantu meringankan beban kota yang kekurangan lahan hijau dan mampu memproduksi bahan pangan bagi warga kota.

Ruang hunian dapat dimanfaatkan sebagai ruang yang memproduksi pangan mandiri. Dengan ruang publik yang adaptif dan produktif diharapkan dapat menyatukan dan meningkatkan kualitas hidup masyarakat dan kota. Jika lahan hijau kota dapat dimanfaatkan untuk memproduksi pangan seperti sayur dan buah-buahan secara gotong-royong maka kebutuhan pangan masyarakat akan terpenuhi.

Sebagai kawasan yang memiliki penduduk yang cukup padat dan juga tingkat pemintaan energi dan pasokan pangan tinggi, Kelurahan Papanggo yang berada di Kecamatan Tanjung Priok membutuhkan sebuah tempat tinggal yang juga bisa berfungsi sebagai tempat beraktivitas untuk meningkatkan produktivitas para warga Kelurahan Papanggo. Oleh karena itu, desain bhiopilic terlihat cocok untuk daerah Papanggo dikarenakan desain biophilic adalah sebuah bangunan yang mampu menyelaraskan kepentingan alam dan manusia (Kellert, 2005). Konteks tempat yang berpenduduk padat, namun dekat dengan Danau Cincin menjadi dua hal berbeda yang saling berhubungan. Manusia yang menjadi subjek biotik dan lingkungannya sebagai abiotik menjadi dasar dalam perancangan. Tujuan penerapan desain Biophilic ke dalam sebuah unit hunian yaitu untuk menciptakan sebuah tempat tinggal yang mampu menghadirkan ruangruang restoratif bagi fisik manusia, menyehatkan sistem syaraf, dan meningkatkan kesejahteraan masyarakat (well-being). 
Urban Farming yang memanfaatkan lahan terbatas akan mengandalkan teknologi baru dan memaksimalkan penggunaan lahan dengan baik, terlebih lagi di daerah perkotaan padat yang minim lahan. Salah satu caranya seperti penyusunan lahan pertanian secara vertikal, atau media tanam yang menumpuk. Urban farming diharapkan dapat membantu meringankan permasalahan kota yang minim lahan hijau agar mampu memproduksi oksigen dan bahan pangan untuk warga kota.

\section{Rumusan Permasalahan}

Setelah latar belakang dijabarkan di atas, rumusan masalah yang didapat: (1) Bagaimana cara untuk mengatasi permasalahan peningkatan kebutuhan akan hunian yang semakin tinggi dengan keterbatasan lahan? (2) Bagaimana cara untuk merancang ruang hunian yang dapat sesuai untuk warga kota baik saat pandemi terjadi dan setelahnya? (3) Bagaimana arsitektur bisa mewadahi aktivitas masyarakat agar tetap produktif selama pandemi dengan pasokan energi yang ada?

\section{Tujuan}

Berdasarkan rumusan masalah di atas, maka tujuan dari proyek vertikal produktif dengan di Papanggo, Jakarta Utara adalah: (1) Menciptakan wadah untuk beraktivitas pada ruang hunian kota, (2) Menciptakan arsitektur yang dapat bergerak cepat dalam waktu, dan dapat melampaui ekologi menuju kehidupan yang lebih baik, dan (3) Memproduksi pangan untuk masyarakat secara langsung.

\section{Manfaat}

Manfaat dari proyek ini di antara lainnya adalah: (1) Menjadikan proyek ini sebagai wadah hunian dan aktivitas warga kota yang lebih baik, (2) Menjadi tempat berkumpul warga setempat yang baru, dan (3) sebagai tempat memproduksi dan menjual hasil bercocok tanam warga Papanggo, Jakarta Utara.

\section{KAJIAN LITERATUR}

\section{Beyond Ecology}

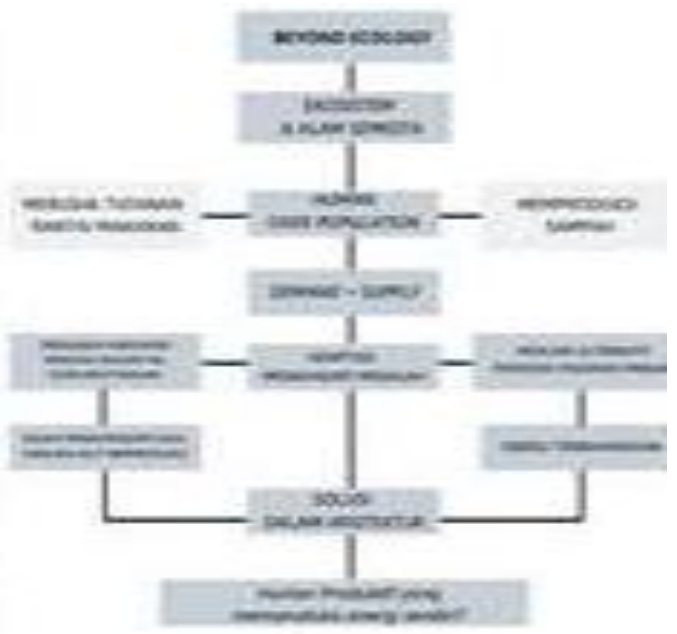

Gambar 2. Framework kerangka berpikir Sumber: Penulis, 2021

Dalam "beyond ecology" terdapat parameter yang jelas dalam arsitektur untuk digunakan sebagai acuan. Apabila sebuah karya arsitektur telah memenuhi minimal empat dari enam parameter dibawah ini, maka karya arsitektur tersebut sudah dapat dianggap "melampaui 
ekologi". Keenam parameter tersebut adalah: context, energy and emission, adaptation, resilience, sustainable digital, dan new technology (Sutanto, 2021).

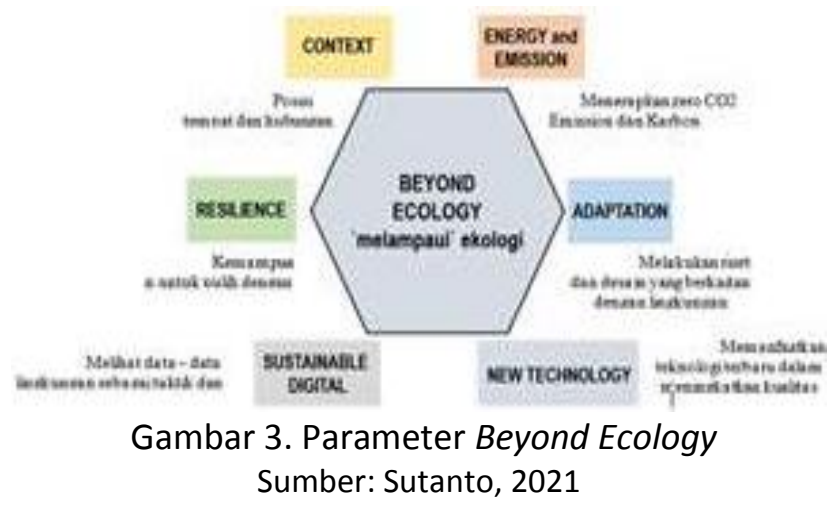

Dari keenam parameter di atas, dipilih empat dari di antaranya, adaptation, resilience, new technology, dan context dengan penerapan program sebagai berikut: (1) Adaptation, penerapan desain yang menyesuaikan keadaan pandemi COVID-19, dimana program hunian produktif diharapkan bisa bertahan di masa bencana lainnya, (2) Resilience, hunian yang mengandalkan energi terbarukan, melampaui ekologi sekarang untuk kehidupan yang lebih baik di masa depan, (3) New Technology, penggunaan mesin-mesin urban farming (hidroponik NFT) dan listrik yang membantu manusia dalam tetap produktif, dan (4) Context, penduduk setempat, ditempatkan sebagai biotik dan lingkungan hidup di tengah kota sebagai abiotik.

\section{Hunian Vertikal}

Hunian merupakan salah satu dari 3 kebutuhan dasar manusia dalam kehidupan (papan, sandang, dan pangan). Menurut Kamus Besar Bahasa Indonesia, "hunian" berarti tempat tinggal atau kediaman, sedangkan "vertikal" berarti tegak lurus dari bawah ke atas atau kebalikannya. Dari kedua kata tersebut, maka hunian vertikal dapat diartikan sebagai sebuah tempat tinggal yang dikonfigurasikan secara tegak lurus dari permukaan bumi.

Perkembangan hunian vertikal mulai muncul untuk menjawab keterbatasan lahan dan sebagai pemenuhan kebutuhan ruang. Hunian vertikal (Vertical Dwellings) tergolong dalam arsitektur vertikal bersifat 'parasit' yang mana tidak hanya sekedar berbicara soal bentuk, ketinggian, ataupun tipologi namun lebih ke konteks dimana arsitektur tersebut dapat tumbuh. Hunian vertikal secara umum memiliki fungsi untuk memenuhi kebutuhan hunian di perkotaan yang terus meningkat seiring berkembangnya pertumbuhan penduduk. Kepadatan penduduk di perkotaan menjadi salah satu faktor dari hadirnya hunian vertikal di tengah kota. Hunian vertikal terdiri dari beberapa jenis, di antaranya adalah apartemen, loft, kondominium, dan rumah susun. Hunian vertikal yang dirancang bukan hanya berfungsi sebagai tempat tinggal, melainkan sebagai tempat warga kota beraktivitas, berkembang, dan dapat aktif memproduksi pangannya secara mandiri (urban farming).

\section{Urban Farming}

Urban farming adalah kegiatan pertanian kota yang dilakukan pada lahan yang terbatas. Di antara metode-metode urban farming yang ada, dipilih metode hidroponik yang menggunakan air agar dapat memanfaatkan sumber daya alam dari lingkungan sekitar, yakni air dari Danau Cincin yang telah difiltrasi dan purifikasi. Metode bercocok tanam yang dipilih adalah hidroponik yang medianya tidak menggunakan tanah melainkan air sebagai media tanam. Untuk menggantikan nutrisi dari tanah, air yang digunakan untuk budidaya tanaman diberi unsur hara yang berisi unsur-unsur penting kebutuhan tanaman. Sistem hidroponik yang digunakan untuk 
tanaman dipilih dua, di antaranya adalah Nutrient Film Technique (untuk tanaman petsai, kentang, cabai, dan Deep Flow Technique (untuk tanaman bawang putih, bawang merah, dan tomat).

\section{METODE}

\section{Metode Penelitian}

Metode yang digunakan adalah metode kualitatif. Berawal dari data lapangan untuk dianalisa dengan teori. Metode ini adalah bentuk pemahaman fenomena tentang apa yang sedang terjadi di suatu tempat, yang dalam pembahasan ini adalah Papanggo, Hasil dari metode ini menekankan pada makna. Pengumpulan data yang didapat lalu dianalisa sesuai dengan kebutuhan masyarakat (user). Penerjemahan data menuju kesimpulan ini menggunakan metode penelitian kualitatif.

Dengan memperhatikan dan menelaah fenomena yang terjadi pada suatu tempat, program arsitektur dapat terbentuk melalui pengumpulan data dan memperhatikan perilaku dan aktivitas warga Papanggo. Kemudian, dicari ciri khas pada Papanggo untuk mengetahui citra apa yang bisa ditunjukkan oleh arsitektur. Citra dari tapak yang padat akan rumah penduduk kota serta Danau Cincin. Dari data dan analisa tersebut akan diterapkan parameter Beyond Ecology (adaptation, resilience, new technology, dan context) untuk menghasilkan arsitektur dengan bertujuan untuk meningkatkan kualitas hidup masyarakat pada suatu tempat.

\section{Taktik dan Strategi}

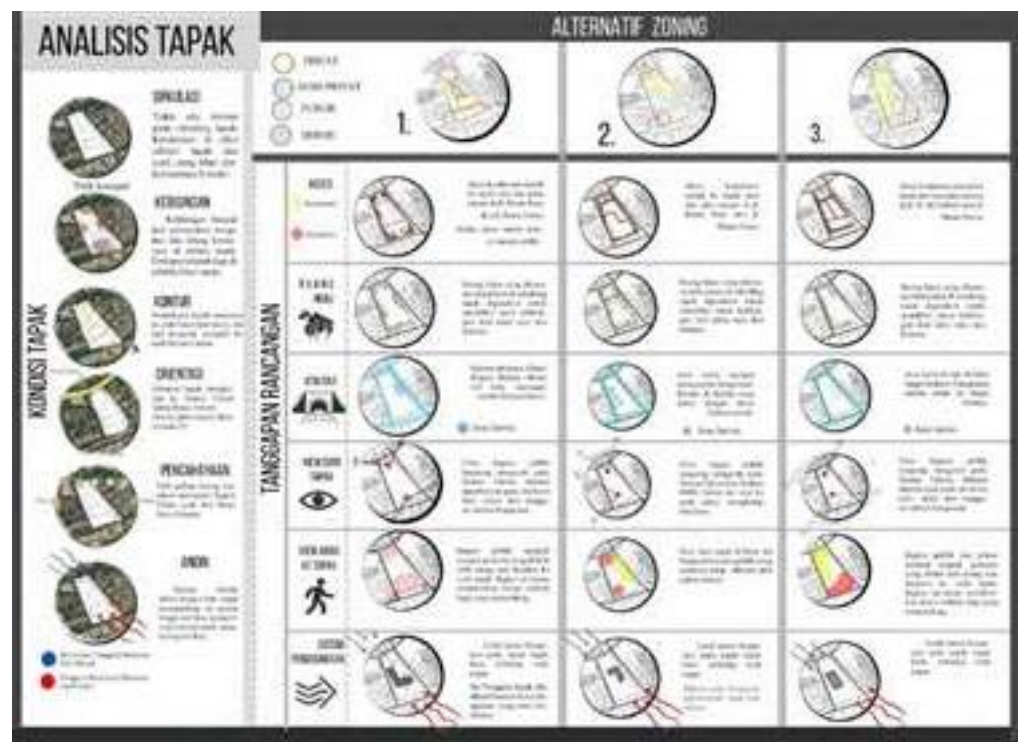

Gambar 4. Analisis Tapak

Sumber: Penulis, 2021

Hal pertama yang dilakukan adalah mengumpulkan data dari internet. Di era Globalisasi, data suatu tempat dapat dengan mudah diakses melalui internet seperti peta, hubungan jalan, nodes, arus lalu lintas, jumlah penduduk dan profesinya. Setelah mengumpulkan data yang dibutuhkan, data diolah dan dianalisa. Data-data existing seperti pencahayaan, view di sekitar tapak, sirkulasi, kontur tanah, kebisingan, dan penghijauan dianalisis dengan tiga alternatif zoning yang telah dibuat. Pengolahan dan analisa ini akan menghasilkan suatu kesimpulan yang akan dikaitkan dengan teori-teori yang ada, dan menentukan zoning terpilih untuk selanjutnya dijadikan dasar dalam mendesain hunian vertikal yang produktif. Peletakkan sirkulasi masuk lalu diharapkan dapat memberikan jawaban dari perancangan arsitektur yang melampaui ekologi sekarang. 


\section{Penerapan Proses Desain}

Desain merupakan hasil dari analisa data pada lapangan dan sebuah teori. Data lapangan membicarakan fakta lapangan dan kebutuhan. Teori merupakan pemikiran seseorang yang dapat diterapkan menjadi sebuah output, dalam kasus ini arsitektur. Penerapan proses desain menggunakan pendekatan biophilic. Istilah biophilic menyatakan bahwa manusia akan lebih sehat dalam lingkungan alam secara fisik maupun psikologi (Sontarigan, 2017).

\section{DISKUSI DAN HASIL}

\section{Data Tapak}

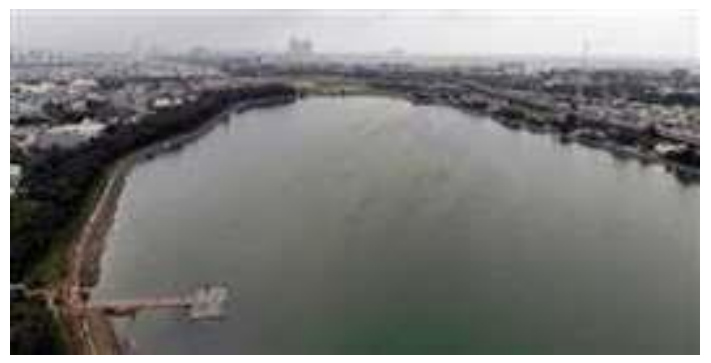

Gambar 5. Danau Cincin

Sumber: Google image

Papanggo merupakan sebuah kelurahan di Kecamatan Tanjung Priok, Jakarta Utara. Kelurahan ini berbatasan dengan Kelurahan Warakas di bagian utara, Kelurahan Sungai Bambu di bagian barat, Kelurahan Sunter Agung di bagian timur dan selatan. Hari ini Papanggo dikenal sebagai daerah pemukiman warga kota yang padat, tempat perdagangan komersil, dan industri. Di Papanggo, ada sebuah waduk yang bernama Danau Cincin dan dimanfaatkan sebagai tempat penampungan air. Perkembangan kelurahan Tanjung Priok juga sangat pesat dikarenakan adanya pembangunan Stadion BMW yang berpotensi tinggi untuk menjadi salah satu pusat atraksi di DKI Jakarta.

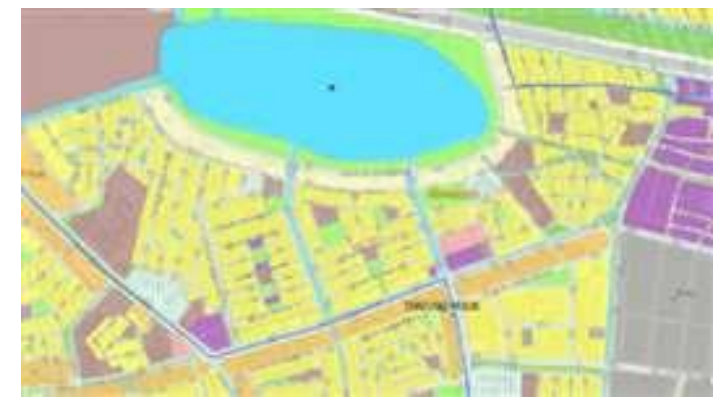

Gambar 6. Tata Guna Lahan

Sumber: Peta Rencana Kota, 2021

Lokasi tapak terpilih berada diujung Papanggo yang berdekatan dengan Danau Cincin. Karena berdekatan dengan tempat penampungan air, terdapat penurunan kontur tanah pada tapak. Tapak berada di jalan kolektif sehingga didominasi oleh pemukiman warga. Luas tapak Kelurahan Papanggo adalah sebesar $17.140 \mathrm{~m}^{2}$. Nilai KDB tapak tersebut adalah sebesar $30 \%$, KLB sebesar 0,9, KDH sebesar 45\%, KB sebesar 30 dan KTB sebesar $40 \%$. 


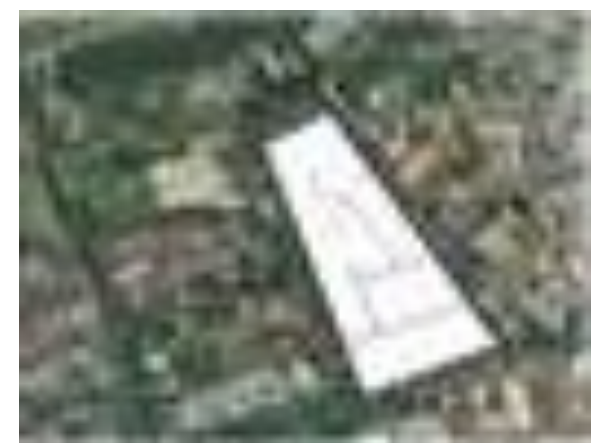

Gambar 7. Tapak dan Lingkungan Eksisting Sumber: Google map

Tapak yang didominasi oleh perumahan yang memiliki kepadatan yang tinggi. Rata-rata warga yang tinggal tetap dan mengkontrak. Pada peta rencana kota, peruntukan tapak terpilih adalah zona perumahan Vertikal KDB rendah. Peruntukan dapat memenuhi fungsi hunian, komersil, dan perdagangan. Tapak dikelilingi oleh perumahan, Danau Cincin, dan kolam pemancingan. Selain itu, terlihat bahwa ada ruang terbuka hijau yang mengelilingi Danau Cincin, tetapi realitanya ruang terbuka hijau belum tertata dengan baik karena pembangunan yang belum merata. Produksi pangan yang menghasilkan sampah juga dapat digunakan sebagai bahan pasokan energi listrik bertenaga biomassa. Dengan letak berada di perumahan, dibutuhkannya fasilitas umum yang adaptif dan produktif bagi masyarakat dan tapaknya. Productive LivingVertical Housing akan mewadahi aktivitas warga dan mengangkat citra Kawasan Papanggo

\section{Aksesibilitas}

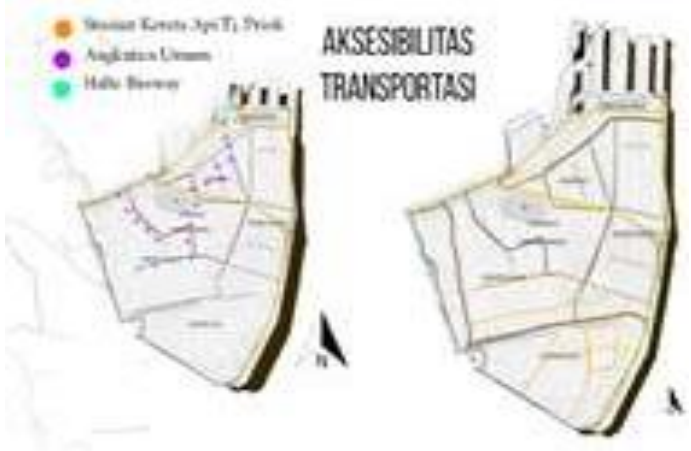

Gambar 8. Analisis Hierarki Jalan Sumber: Penulis, 2021

Hierarki jalan menurut gambar di atas: (1) Kuning: Jalan Arteri Primer, (2) Cokelat: Jalan Sekunder, (3) Oranye: Jalan Kolektor, (4) Abu-abu: Jalan Lokal. Kelurahan Papanggo adalah salah satu kelurahan yang memiliki luas $11 \%$ dari luas Kecamatan Tanjung Priok adalah $2,82 \mathrm{~km}^{2}$. Dengan jumlah KK sebanyak 13,739 yang terdiri 13 RW, 127 RT dan jumlah penduduk 44.724 jiwa. Mayoritas pengguna Jalan Bisma Raya masih menggunakan kendaraan pribadi. Akses dan fasilitas transportasi publik belum tersedia di sekeliling tapak. Untuk mencapai tapak terpilih hanya bisa menggunakan kendaraan pribadi, jalan kaki, atau menggunakan ojek online. Transportasi publik terdekat berada pada radius $800 \mathrm{~m}$ dari tapak terpilih.

Pada lokasi tapak terpilih, belum tersedia jalur untuk pedestrian. Mayoritas pengguna jalan menggunakan kendaraan pribadi. Kurangnya rasa aman membuat masyarakat jarang untuk berjalan kaki. Dengan adanya pedestrian akan menciptakan keamanan dan keindahan pada ruang kota. 


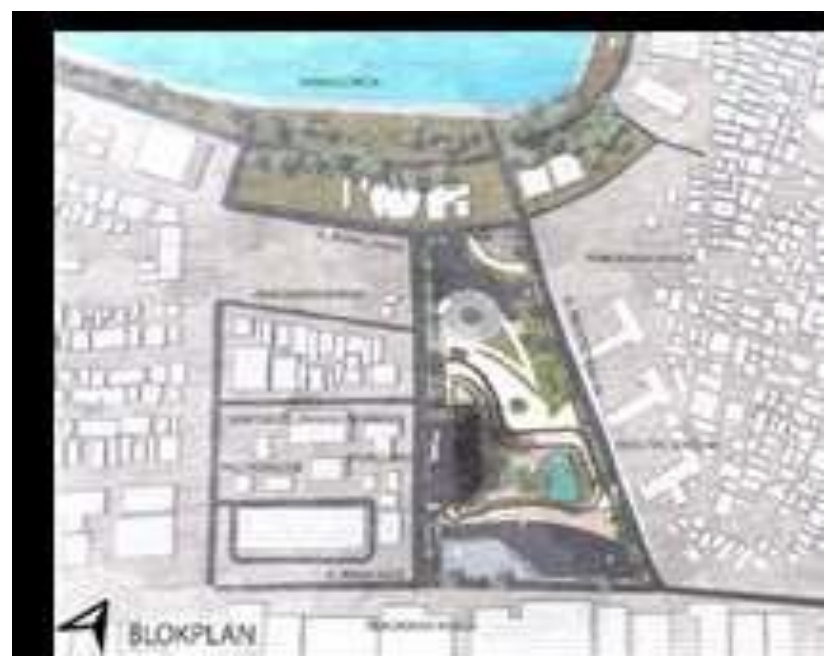

Gambar 9. Blokplan

Sumber: Penulis, 2021

Keterangan:
1. Akses masuk
5. Apartemen 17 lantai
2. Akses keluar
6. Podium
3. Akses servis
7. Drop Off
4. Amphitheater
8. Parkir sepeda/tamu

\section{Usulan Aktivitas dan Program}

Tapak yang direncanakan untuk program tempat tinggal masyarakat berada di lahan seluas $17.140 \mathrm{~m}^{2}$. Program yang diusulkan adalah hunian vertikal yang dapat menjadi tempat tinggal bagi warga kota yang padat. Untuk memanfaatkan lahan yang terbatas secara maksimal, hunian vertikal yang bertipe apartemen. Apartemen merupakan jenis hunian vertikal yang terdiri dari area privat, area komunal, dan komersial. Penghuni dapat melakukan aktivitasnya di unit apartemennya masing-masing, lalu melakukan interaksi dengan penghuni lainnya pada fasilitas umum seperti clubhouse, taman terbuka, dan area urban farming.

Tabel 1. Luas Program Apartemen

\begin{tabular}{|c|c|}
\hline Luas lahan & $17.140 \mathrm{~m}^{2}$ \\
\hline Building Coverage (KDB) $30 \%$ & $5.142 \mathrm{~m}^{2}$ \\
\hline Luas Bangunan (Gross Floor Area) 0,9 & KLB $0,9 \times 17.140 \mathrm{~m}^{2}=15.426 \mathrm{~m}^{2}$ \\
\hline Ruang Terbuka Hijau & $\mathrm{KDH} 45 \% \times 17.140 \mathrm{~m}^{2}=7.713 \mathrm{~m}^{2}$ \\
\hline $\begin{array}{l}\text { Luas Nett Apartemen } \\
\text { (Koefisien Nett Apartemen 0,64) }\end{array}$ & $\begin{array}{l}\text { Luas Bangunan } \mathrm{x} \text { Koefisien Perbandingan GFA: NFA untuk } \\
\text { Apartemen }=15.426 \mathrm{~m}^{2} \times 0,64=9.872,64\end{array}$ \\
\hline $\begin{array}{l}\text { Luasan Unit yang dijual } \\
\text { (Semi Gross Apartemen) }\end{array}$ & $\begin{array}{l}\text { Luas Nett Apartemen }+ \text { Sirkulasi } 30 \% \\
9.872,64+30 \%=9.872,64 \mathrm{~m}^{2}+2.961,7 \mathrm{~m}^{2}=12.834,43 \mathrm{~m}^{2}\end{array}$ \\
\hline $\begin{array}{l}\text { Luas Fasilitas, Kantor Pengelola, dan } \\
\text { Service }\end{array}$ & $\begin{array}{l}\text { Luas Gross Floor - Luas Semi Gross Apartemen } \\
15.426 \mathrm{~m}^{2}-12.834,43 \mathrm{~m}^{2}\end{array}$ \\
\hline Luas Basement (KB 30\%) & $5.142 \mathrm{~m}^{2}$ \\
\hline
\end{tabular}

Sumber: Penulis, 2021

Usulan aktivitas untuk menjawab permasalahan, kebutuhan, dan potensi dalam lingkungan maupun masyarakat disusun Kembali dengan konsep Diagram Programming, dikaitkan dengan kegiatan aktivitas warga atas prinsip bahwa ruang dapat membantu rutinitas warga setempat dalam berinteraksi dalam ikatan kebersamaan baik dalam keluarga maupun hubungan antarkeluarga di daerah setempat. Program yang diusulkan adalah hunian vertikal yang produktif dengan memproduksi energi secara mandiri. 


\section{Analisis Gubahan Massa}

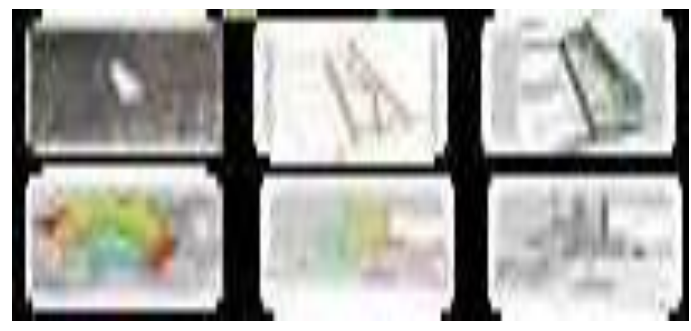

Gambar 10. Analisis Zoning pada Bangunan Sumber: Penulis, 2021

Konsep desain bangunan ini memiliki konsep massa yang mengikuti pola tapak yang terinspirasi bentuk alam, yaitu lengkungan yang seperti tangkai daun 'tanaman'. Koneksi material dengan alam seperti penggunaan bahan parket bermotif kayu, pemakaian unsur alam seperti batu dan kayu pada material bangunan. Kemudian koneksi visual dan non-visual dengan alam dengan peletakkan tanaman di balkon unit apartemen agar penghuni dapat melakukan koneksi nonvisual seperti bersentuhan dengan tanaman atau menghirup aroma dan koneksi visual seperti melihat langsung dengan adanya sarana taman terbuka hijau di area luar clubhouse yang berdekatan dengan kolam renang.
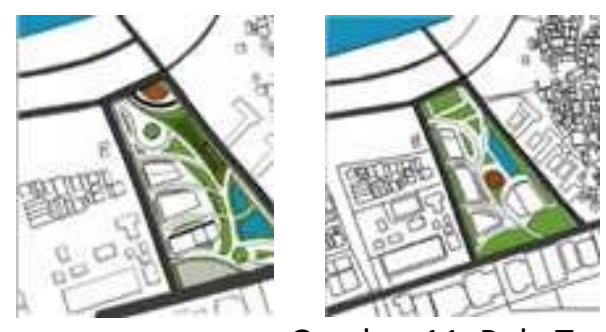

Gambar 11. Pola Tapak

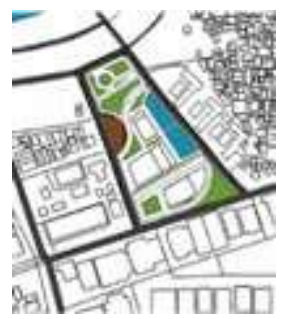

Sumber: Penulis, 2021

\section{Konsep Bangunan}

Konsep yang diterapkan pada apartemen SOHO di Kota Pekanbaru adalah the Living Hills. Konsep ini sesuai dengan prinsip Biophilic Design yaitu biomorphic forms and patterns (bentuk dan pola biomorfik) dan complexity and order (kompleksitas dan keteraturan). Konsep yang diterapkan pada apartemen ini merupakan productive living yang mendekatkan manusia dengan lingkungannya. Konsep ini sesuai dengan pendekatan Biophilic. Ada beberapa prinsip yang digunakan, yaitu biomorphic forms and patterns (bentuk dan pola biomorfik) dan complexity and order (kompleksitas dan keteraturan).
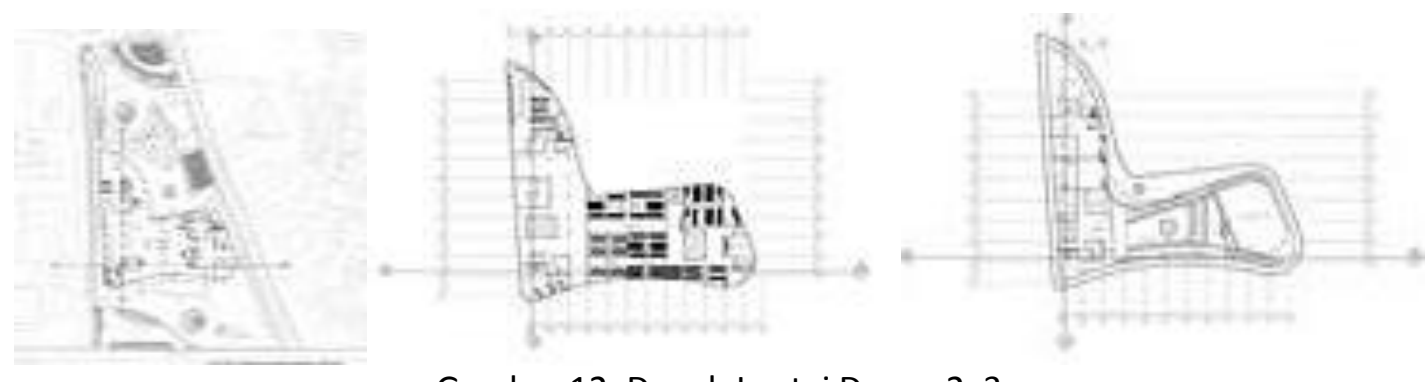

Gambar 12. Denah Lantai Dasar, 2, 3

Sumber: Penulis, 2021 

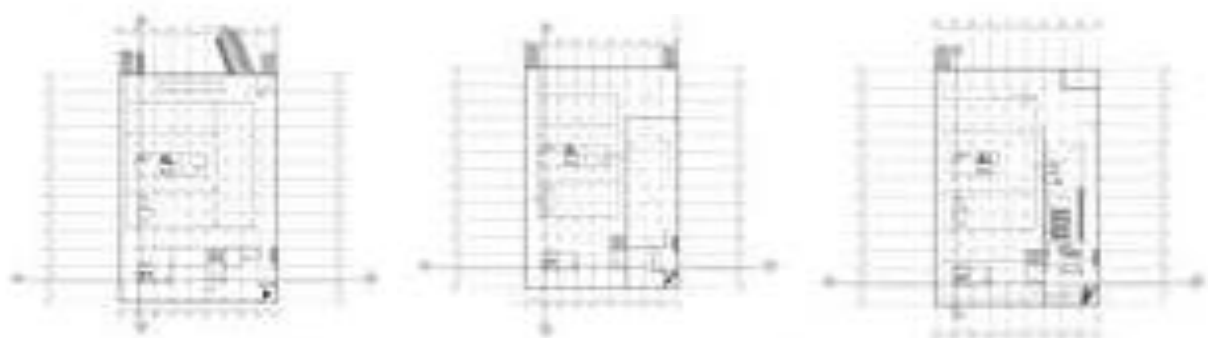

Gambar 13. Denah Lantai Basement 1,2,3

Sumber: Penulis, 2021

Modul Unit Apartemen

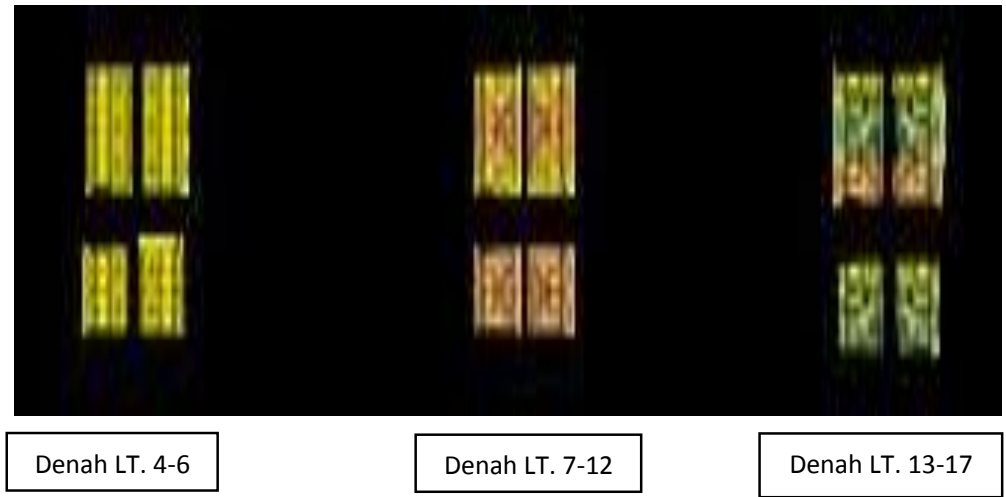

Gambar 14. Denah Lantai Tipikal Apartemen Sumber: Penulis, 2021

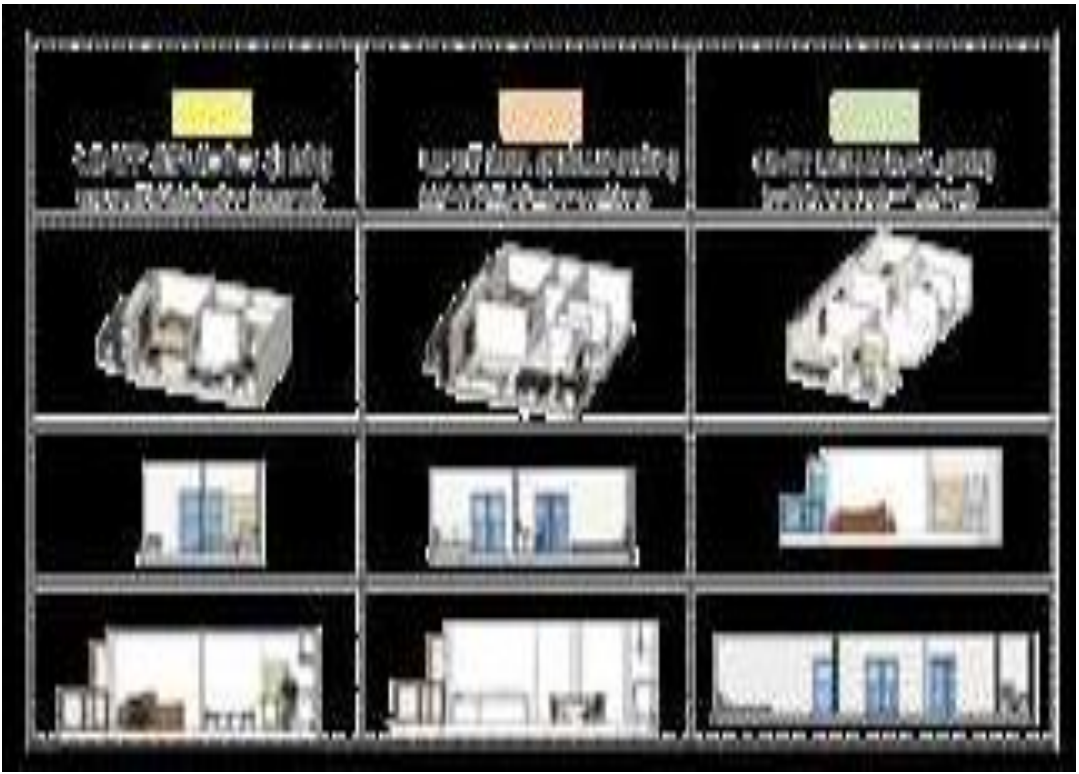

Gambar 15. Tipe Unit Apartemen

Sumber: Penulis, 2021

Total dari lantai tipikal unit apartemen adalah 13 lantai dengan total penduduk 396 warga penghuni apartemen. Pada lantai 4-6 terdapat 20 unit/lantai yang berarti unit studio pada lantai tipikal ini berjumlah 60 unit (120 orang), lalu pada denah lantai tipikal yang kedua terdapat rincian unit studio (24 unit) dan unit keluarga dengan dua kamar tidur (12 unit) yang 
berpenghuni 96 orang warga. Pada denah lantai tipikal yang terakhir, terdapat 20 unit studio, 10unit 2BR, dan 20 unit 3BR dengan perkiraan memiliki 180 orang warga.

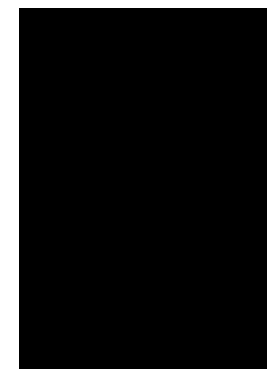

DENAH STUDIO (1BR)

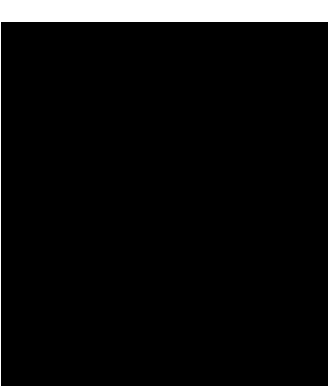

DENAH 2BR

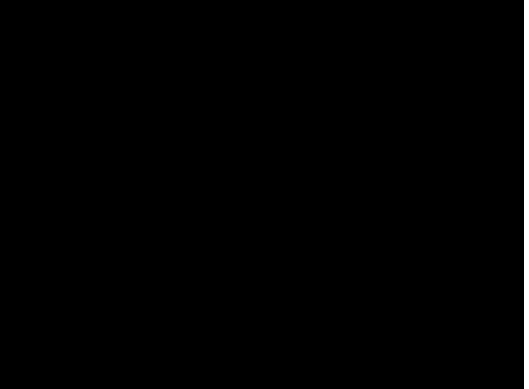

DENAH 3BR

Gambar 16. Denah Modul Unit Apartemen

Sumber: Penulis, 2021

\section{Modul Unit Urban Farming}

Urban farming merupakan kegiatan yang dilakukan oleh penghuni maupun Penghuni unit apartemen terlibat dalam kegiatan urban farming di unit apartemen mereka masing-masing dengan menanam tumbuhan pada area luar balkon pribadinya. Untuk bagian urban farming hidroponik di lantai 2, melibatkan staff dari warga sekitar Papanggo. Kegiatan penunjang yang ada lainnya adalah urban farming yang menggunakan metode hidroponik NFT (Nutrient Film Technique) dan DFT (Deep Flow Technique).

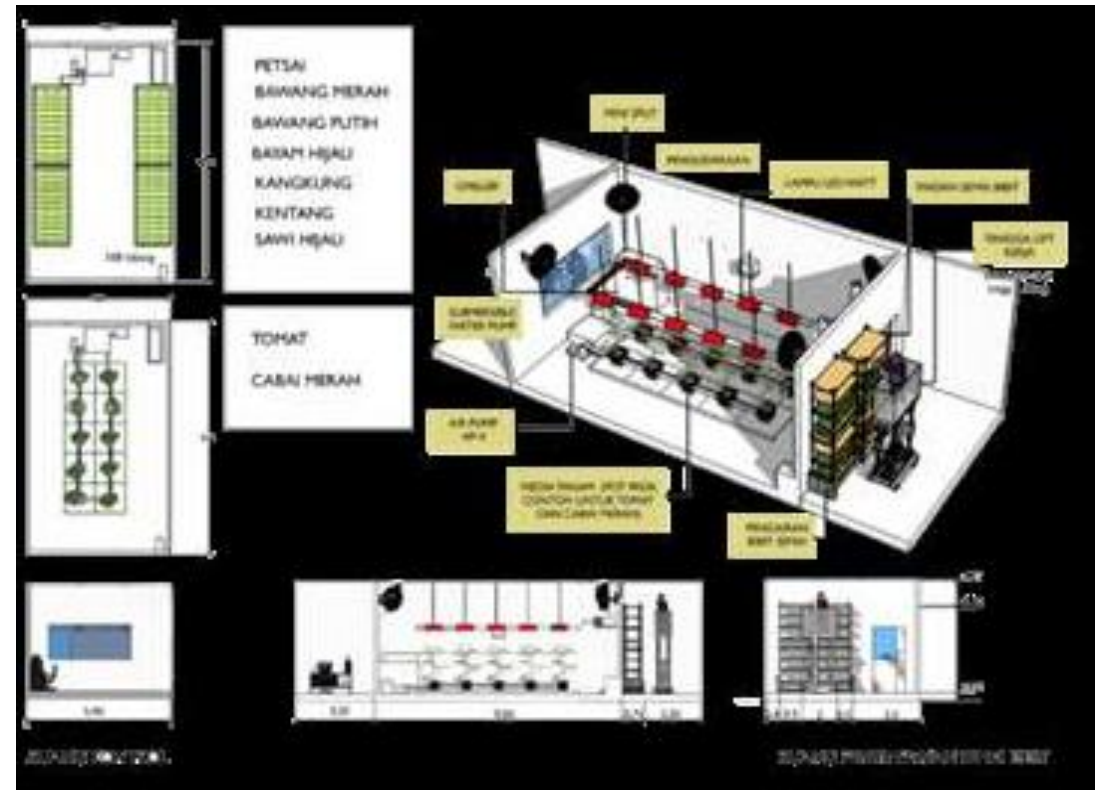

Gambar 17. Modul Unit Budidaya Hidroponik

Sumber: Penulis, 2021

Metode yang digunakan pada program urban farming di apartemen ini merupakan hidroponik. Air dari Danau Cincin yang telah difiltrasi dan dipurifikasi, kemudian dimanfaatkan sebagai suplai air yang menggerakkan sistem yang ada. Perhitungan kebutuhan dari unit urban farming bertumpu pada data kependudukan Papanggo yang berjumlah 46.141 jiwa. Dengan perumpamaan tiap warga membutuhkan 1 ikat sayur/hari yang berarti total kebutuhan masyarakat Papanggo adalah 1.384.230 ikat sayur/bulan. Lalu dianggap bahwa dengan luas 1 
Ha yang dapat menghasilkan 1.750 ikat, maka harus dilakukan 26 kali siklus panen/hari (790 kali/bulan). Setelah itu, 26 siklus panen dibagi menjadi 9 jenis tanaman dan ada tiga set tanaman yang dipanen tiap hari. Kelebihan panen dijadikan raw product atau diproses pada cafe atau restoran.

Hasil akhir dari urban farming pasti akan menghasilkan sampah organik. Untuk mewujudkan lingkungan yang lebih sehat dan bersih, sampah kemudian diolah kembali menjadi briket sampah. Setiap $1 \mathrm{~kg}$ briket sampah atau briket biomassa yang digunakan sebagai bahan bakar gasifier akan menghasilkan gas biomassa dengan volume $2.185 \mathrm{~m}^{3}$ atau setara dengan listrik sebesar 0,75 kWh (Sundadjaya, 2016). Hasil samping dari gasifikasi ini adalah abu dan arang, yang bisa digunakan sebagai pupuk tanaman.

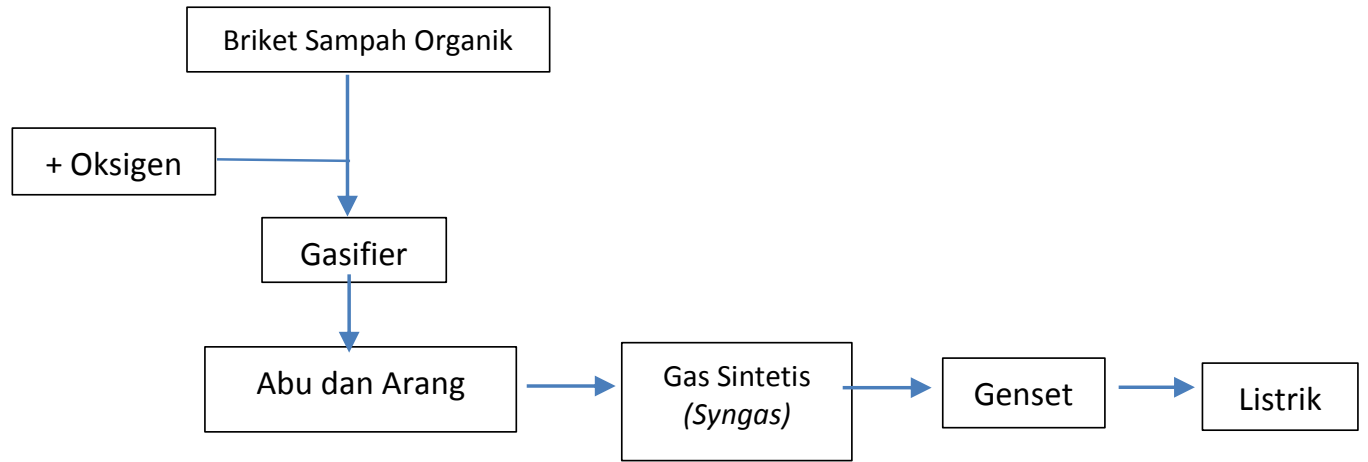

Gambar 18. Alur Proses Sampah Organik menjadi Energi Biomassa Sumber: Sundadjaya, 2016

Keuntungan dari penerapan sistem ini yaitu dapat meningkatkan efektifitas lahan dan efisiesi energi. Lahan yang digunakan adalah lahan yang sama dan dapat dilakukan di lahan yang terbatas. Sistem ini juga ramah lingkungan karena berkonsep zero waste.

Tabel 2. Perbandingan Biaya Produksi dan Jual

\begin{tabular}{|c|c|c|c|c|c|c|c|}
\hline \multirow[b]{2}{*}{ PRODUK } & \multicolumn{6}{|c|}{ BIAYA PRODUKSI } & \multirow[b]{2}{*}{$\begin{array}{c}\text { BIAYA } \\
\text { JUAL / kg } \\
\text { di } \\
\text { ORGANIC } \\
\text { MARKET } \\
\text { (ditinjau } \\
\text { dari harga } \\
\text { pasaran) }\end{array}$} \\
\hline & $\begin{array}{c}\text { Biaya } \\
\text { Bibit (1kg) }\end{array}$ & $\begin{array}{c}\text { Biaya } \\
\text { Listrik } \\
\text { Pomp } \\
\text { a } \\
\text { (PER- } \\
\text { HARI) }\end{array}$ & $\begin{array}{c}\text { Lama Penyinara } \\
\text { n (40WATT) }>10 \\
\text { lampu }\end{array}$ & $\begin{array}{c}\text { Biaya } \\
\text { Listrik } \\
\text { Per-hari } \\
\text { (per 1 } \\
\text { kwh } \\
\text { Rp1.352) }\end{array}$ & $\begin{array}{c}\text { Biaya } \\
\text { Pupuk } \\
+ \\
\text { Nutrisi }\end{array}$ & $\begin{array}{l}\text { Biaya } \\
\text { Media }\end{array}$ & \\
\hline $\begin{array}{c}\text { Petsai } \\
\text { Sawi } \\
\text { Putih } \\
\text { Dakora } \\
\text { (Cap } \\
\text { Panah } \\
\text { Merah) }\end{array}$ & $\begin{array}{l}\text { Rp } 125.00 \\
0 .\end{array}$ & $\begin{array}{l}280 \\
\text { watt } \\
\text { per } \\
\text { jam= } \\
24 \text { jam } \\
> \\
6.720\end{array}$ & $\begin{array}{l}10-13 \mathrm{JAM} / \mathrm{HARI} \\
=13 \times 40 \times 10 \\
=5.200 \mathrm{watt}= \\
5,2 \mathrm{kwh}\end{array}$ & $\begin{array}{c}11,92= \\
16.115,8 \\
4\end{array}$ & $\begin{array}{l}20.000 / \\
\mathrm{kg} \times 9 \\
\text { jenis } \\
\text { tanama } \\
\mathrm{n}= \\
180.00 \\
0 \text { untuk }\end{array}$ & $\begin{array}{l}\text { Menggu } \\
\text { nakan } \\
\text { Pipa \& } \\
\text { Rockwoo } \\
\text { I }\end{array}$ & $\begin{array}{c}\text { Rp. } \\
15.300 / \mathrm{kg}\end{array}$ \\
\hline $\begin{array}{l}\text { Kentang } \\
\text { Granola } \\
\text { G0 }\end{array}$ & $\begin{array}{l}\text { Rp. } \\
250.000\end{array}$ & $\begin{array}{l}\text { WATT } \\
=6,72 \\
\text { kwh }\end{array}$ & $\begin{array}{l}14 \mathrm{JAM} / \text { hari }= \\
14 \times 40 \times 10 \\
=5.600 \mathrm{watt}= \\
5,6 \mathrm{kwh}\end{array}$ & $\begin{array}{l}12,32= \\
16.656\end{array}$ & 9 set & & $\begin{array}{c}\mathrm{Rp} . \\
18.000 / \mathrm{kg}\end{array}$ \\
\hline $\begin{array}{l}\text { Cabai } \\
\text { Merah }\end{array}$ & $\begin{array}{l}\text { Rp. } \\
400.000\end{array}$ & & $\begin{array}{l}10-12 \mathrm{JAM} / \mathrm{HARI} \\
12 \times 40 \times 10= \\
4.800 \text { watt }=5,6 \\
\text { kwh }\end{array}$ & 16.656 & & $\begin{array}{c}\text { Menggu } \\
\text { nakan } \\
\text { wadah } \\
\text { pot yang }\end{array}$ & $\begin{array}{c}\text { Rp. } \\
\text { 100.000/k } \\
\text { g }\end{array}$ \\
\hline
\end{tabular}




\begin{tabular}{|c|c|c|c|c|c|c|c|}
\hline \multirow[b]{2}{*}{ PRODUK } & \multicolumn{6}{|c|}{ BIAYA PRODUKSI } & \multirow[b]{2}{*}{$\begin{array}{c}\text { BIAYA } \\
\text { JUAL /kg } \\
\text { di } \\
\text { ORGANIC } \\
\text { MARKET } \\
\text { (ditinjau } \\
\text { dari harga } \\
\text { pasaran) }\end{array}$} \\
\hline & $\begin{array}{c}\text { Biaya } \\
\text { Bibit (1kg) }\end{array}$ & $\begin{array}{c}\text { Biaya } \\
\text { Listrik } \\
\text { Pomp } \\
\text { a } \\
\text { (PER- } \\
\text { HARI) }\end{array}$ & $\begin{array}{c}\text { Lama Penyinara } \\
\text { n (40WATT) }>10 \\
\text { lampu }\end{array}$ & $\begin{array}{c}\text { Biaya } \\
\text { Listrik } \\
\text { Per-hari } \\
\text { (per 1 } \\
\text { kwh } \\
\text { Rp1.352) }\end{array}$ & $\begin{array}{c}\text { Biaya } \\
\text { Pupuk } \\
+ \\
\text { Nutrisi }\end{array}$ & $\begin{array}{l}\text { Biaya } \\
\text { Media }\end{array}$ & \\
\hline $\begin{array}{c}\text { Tomat } \\
\text { Servo F1 } \\
\text { Hidropon } \\
\text { ik } \\
\text { (Cap } \\
\text { Panah } \\
\text { Merah) } \\
\end{array}$ & $\begin{array}{l}\text { Rp. } \\
1.000 .000\end{array}$ & & $\begin{array}{l}11-14 \text { JAM/HARI } \\
14 \times 40 \times 10= \\
5.600 \text { watt = 5,6 } \\
\text { kwh }\end{array}$ & 16.656 & & $\begin{array}{c}\text { bisa } \\
\text { digunaka } \\
\mathrm{n} \text { berkali } \\
\text { hingga } \\
\text { rusak }\end{array}$ & $\begin{array}{c}\text { Rp. } \\
10.000 / \mathrm{kg}\end{array}$ \\
\hline $\begin{array}{l}\text { Bawang } \\
\text { Merah } \\
\text { Hibrida } \\
\text { (Daily } \\
\text { Farm) }\end{array}$ & $\begin{array}{l}\text { Rp. } \\
2.000 .000\end{array}$ & & $\begin{array}{l}12 \mathrm{JAM} / \mathrm{HARI} \\
12 \times 40 \times 10= \\
4.000 \text { watt }=4 \\
\text { kwh }\end{array}$ & $\begin{array}{c}14.493,4 \\
4\end{array}$ & & & $\begin{array}{c}\text { Rp. } \\
29.000 / \mathrm{kg}\end{array}$ \\
\hline $\begin{array}{c}\text { Kangkun } \\
\text { g }\end{array}$ & Rp. 80.000 & & $\begin{array}{l}3-4 \text { jam }=4 \times 40 \\
\times 10=1.200= \\
1,2 \mathrm{kwh}\end{array}$ & $\begin{array}{c}10.707,8 \\
4\end{array}$ & & & $\begin{array}{c}\text { Rp. } \\
20.000 / \mathrm{kg}\end{array}$ \\
\hline $\begin{array}{c}\text { Bayam } \\
\text { Hijau }\end{array}$ & $\begin{array}{l}\text { Rp. } \\
1.250 .000\end{array}$ & & $\begin{array}{l}3-4 \text { jam } \\
4 \times 40 \times 10= \\
1.600=1,6 \mathrm{kwh}\end{array}$ & $\begin{array}{c}11.248,6 \\
4\end{array}$ & & & $\begin{array}{c}\text { Rp. } \\
15.000 / \mathrm{kg}\end{array}$ \\
\hline $\begin{array}{l}\text { Sawi } \\
\text { Hijau }\end{array}$ & $\begin{array}{l}\text { Rp. } \\
666.666\end{array}$ & & $\begin{array}{l}10-13 \text { jam } \\
13 \times 40 \times 10= \\
5.200 \text { wat } t=5,2 \\
\text { kwh }\end{array}$ & $\begin{array}{c}16.115,8 \\
4\end{array}$ & & & $\begin{array}{c}\mathrm{Rp} . \\
15.000 / \mathrm{kg}\end{array}$ \\
\hline $\begin{array}{l}\text { Bawang } \\
\text { Putih } \\
\text { Kating }\end{array}$ & Rp. 80.000 & & $\begin{array}{l}6 \text { jam perhari } \\
6 \times 40 \times 10= \\
2400 \text { watt }=2,4 \\
\text { kwh }\end{array}$ & $\begin{array}{c}12.330,2 \\
4\end{array}$ & & & $\begin{array}{c}\text { Rp. } \\
28.000 / \mathrm{kg}\end{array}$ \\
\hline
\end{tabular}

Sumber: Harga Pasar, 2021

\section{Deskripsi Desain}

Dari sisi eksterior, bangunan didesain menggunakan bahan material alam dan selaras dengan lingkungan sekitar, yang sebagian besar merupakan ruko dan rumah warga dengan bentuk yang cenderung kotak dan beratap tropis. Bentukan tidak dibuat seakan-akan menjadi alien atau asing di tapak, namun menjadi satu dalam kawasan, dengan tetap memberikan suatu ciri dan membentuk kawasan. Desain juga dibuat untuk memberikan kesan keterbukaan dan permeabilitas, baik dengan fasad yang memaksimalkan bukaan, ataupun dengan keberadaan area tangga yang menghubungkan secara langsung area luar dan dalam bangunan, sekaligus dari muka tanah langsung ke lantai lain di bangunan. Area tangga juga menjadi ruang publik yang terintegrasi dengan ruang luar dari bangunan, yang didesain selaras dengan massa proyek yang dibuat seterbuka mungkin, untuk memaksimalkan konsep openness. 


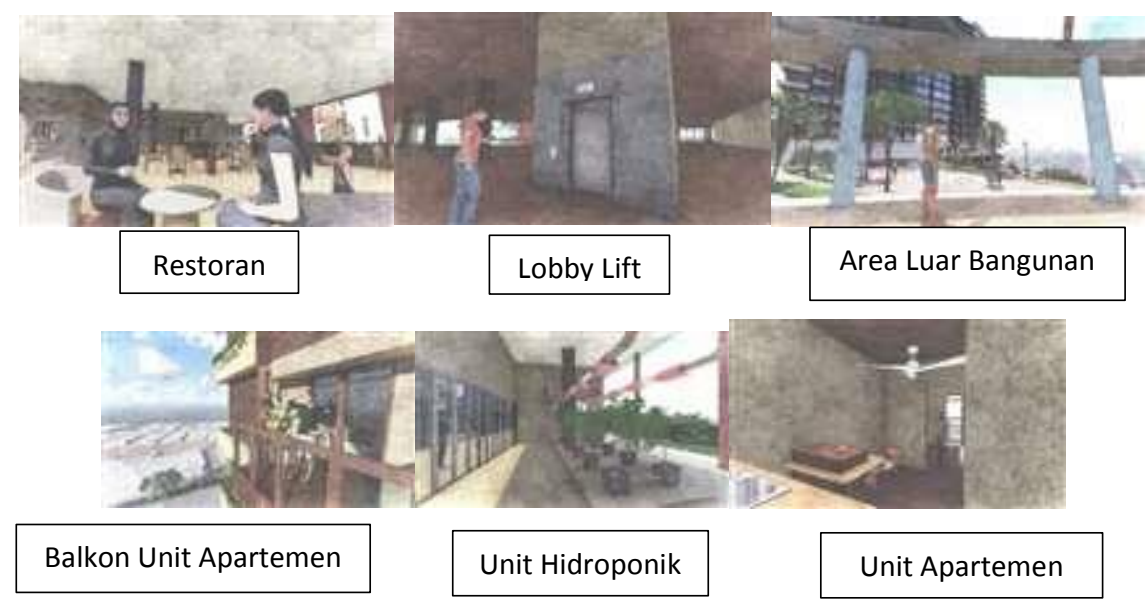

Gambar 19. Perpektif Apartemen

Sumber: Penulis, 2021

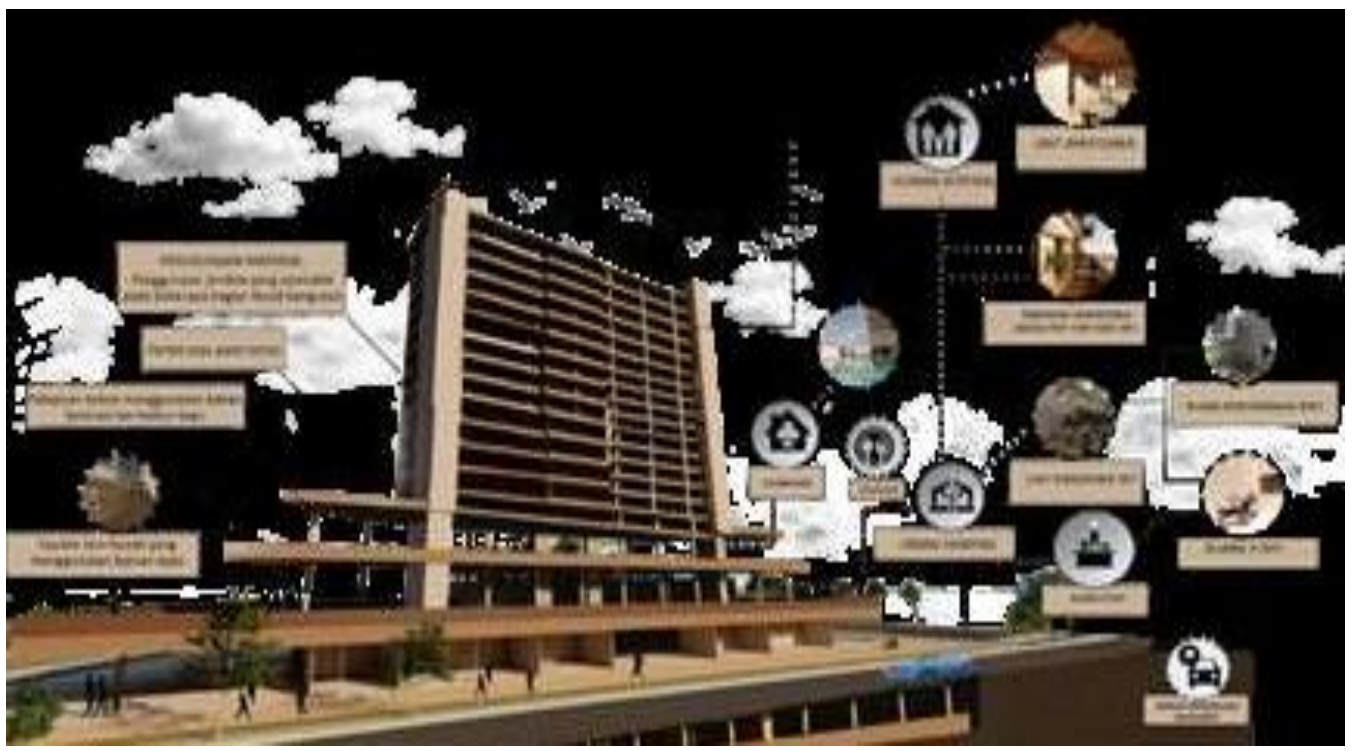

Gambar 20. Potongan Perspektif

Sumber: Penulis, 2021

Struktur bangunan menggunakan beton bertulang, dengan ukuran kolom $60 \mathrm{~cm} \times 60 \mathrm{~cm}$ dan balok berukuran $50 \mathrm{~cm} \times 100 \mathrm{~cm}$. Fasad bangunan di bagian lantai tipikal menggunakan beton precast dengan finishing kayu, dengan balkon unit apartemen yang pintu dan jendela yang openable. Dengan pintu dan jendela apartemen yang terbuka, pencahayaan dan sirkulasi udara alami di pun bisa di. Material-material yang berunsur alam dan sebagai pembentuk fasad dimasukkan selain untuk mendukung konsep keberlanjutan (sustainable) Ruang-ruang interior, seperti restoran, clubhouse, organic market, dan lain-lainnya didesain memaksimalkan pencahayaan alami, untuk mendukung konsep arsitektur terbarukan. Material penghias interior pun tetap mengusahakan bahan-bahan yang berunsur alam dan recycle, sebagai pendukung konsep sustainable dan menciptakan citra program yang menekankan pendekatan alam kepada para pengguna di tengah perkotaan padat. 


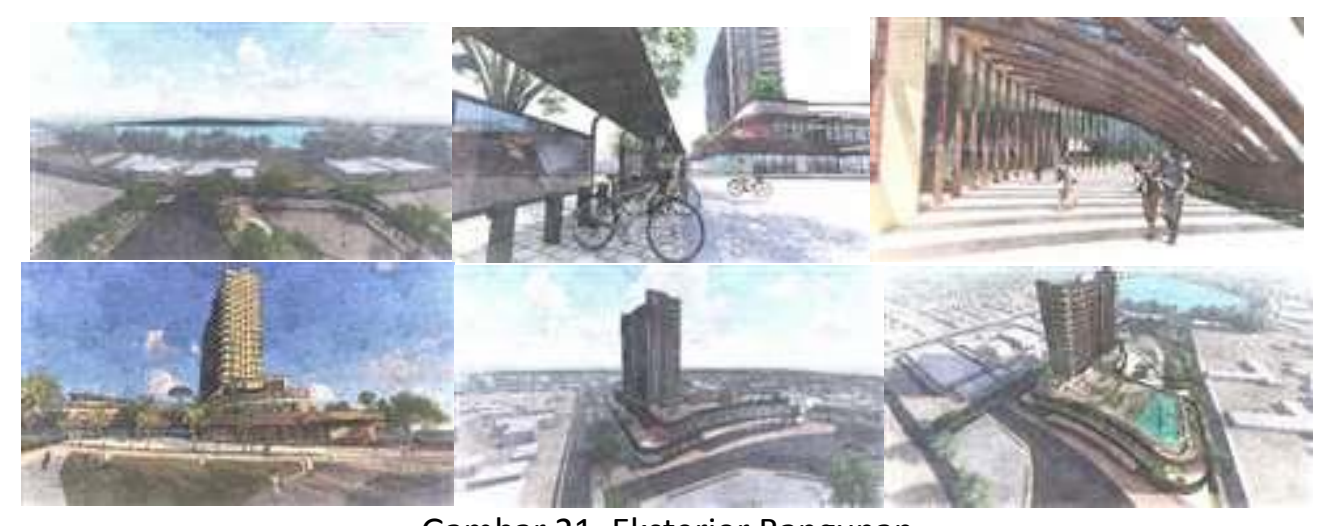

Gambar 21. Eksterior Bangunan

Sumber: Penulis, 2021

\section{KESIMPULAN DAN SARAN}

\section{Kesimpulan}

Dalam perancangan hunian vertikal produktif di Papanggo, Jakarta Utara diambil empat parameter Beyond Ecology (arsitektur yang melampaui ekologi), yaitu adaptation, resilience, new technology, dan context. Perencanaan proyek ini bertujuan untuk memberikan warga kota sebuah hunian yang produktif dengan menghasilkan pangan dan energi secara mandiri dengan teknologi-teknologi baru seperti hidroponik dan sistem pembangkit tenaga listrik biomassa. Selain itu, penerapan kontekstual pada bangunan ini diharapkan dapat menjadi titik kumpul aktivitas warga Papanggo, dan membentuk sebuah lingkungan hidup yang lebih baik dari sebelumnya. Arsitektur hadir di tengah-tengah masyarakat perkotaan untuk menjadi sebuah alat.

\section{Saran}

Terlepas dari pendekatan dan metode yang digunakan pada bangunan ini diperlukan kajian yang lebih mendalam mengenai dampak negatif dari pembangunan apartemen tersebut, termasuk berapa presentase perkerasan yang dirancang sehingga tidak menutup daerah penyerapan air hujan. Papanggo merupakan daerah yang rawan banjir, karena berada di dataran rendah dan dekat dengan laut, hal ini harus lebih diperhatikan dalam merancang lingkungan hidup yang baik.

\section{REFERENSI}

Fauzi, A., Ichniarsyah, A., \& Agustin, H. (2016). Pertanian Perkotaan Urgensi, Peranan, dan Praktik Terbaik.

Kaffah, F., Firzal, Y., \& Susilawaty, M. (2020). Penerapan Prinsip Biophilic Design pada Perancangan Apartemen Soho di Kota Pekanbaru.

Kamus Besar Bahasa Indonesia . (2021). Retrieved from Kamus Besar Bahasa Indonesia Hunian: https://kbbi.web.id/hunian

Kamus Besar Bahasa Indonesia. (2021). Retrieved from Kamus Besar Bahasa Indonesia Vertikal: https://kbbi.web.id/vertikal

Kellert, S. R. (2005). Building for Life: Designing and Understanding the Human-Nature Connection.

Pramarti, A., Yuliani, S., \& Kusumaningdyah. (2016). Apartemen dengan Pendekatan Desain Biophilik di Jakarta Selatan.

Pramudito, S., Lanang, A., \& Jeffry, D. (2018). Studi Model Rancangan Hunian Vertikal Berdasarkan Bentuk Interaksi Warga di Bantaran Sungai Winogo Yogyakarta.

Sontarigan, F. (2017). Panduan Desain Arsitektur dengan Pendekatan Biophilic Design pada Bangunan Perkantoran. 
Sundadjaya, S. (2016). Pembangkit Listrik Tenaga Biomassa Briket Sampah. Inisiatif Listrik Kerakyatan. Jakarta: Penerbit Jurusan Teknik Mesin STT-PLN.

Sutanto, A. (2021). Dromos Oikos. Jakarta. 